\title{
Do romantic partners' responses to provoked vestibulodynia affect women's experience of pain? The roles of catastrophizing and self-efficacy
}

Running Head: Partners' Influence on Entry Dyspareunia

Ashley J. Lemieux, MA*, Sophie Bergeron, PhDæ, Marc Steben, $\mathrm{MD}^{\circ}$, Bernard Lambert, MD $\dagger$

* Departement of Sexology, Université du Québec à Montréal, Montréal, Québec, Canada; aDepartment of Psychology, Université de Montréal, Montréal, Québec, Canada; 'STI Unit, Institut national de santé publique du Québec, Montréal, Québec, Canada; †VUVA Clinic, Centre Hospitalier de l'Université de Montréal—Hôpital St-Luc, Montréal, Québec, Canada

Corresponding Author: Sophie Bergeron, $\mathrm{PhD}$, Department of Psychology, Université de Montréal, C.P. 6128 succursale Centre-Ville, Montréal, Québec, H3C 3J7, Canada.

Tel.: (514) 343-6111 \# 5353; Fax: (514) 343-2285; E-mail: sophie.bergeron.2@umontreal.ca

This research was supported by a Centre de Recherche Interdiscipliaire sur les Problèmes Conjuguaux et les Aggressions Sexuelles scholarship awarded to Ashley J. Lemieux and a Canadian Institutes of Health Research grant to Sophie Bergeron. Furthermore, we thank Mylène Desrosiers and Gaëlle Piché, research coordinators, for their assistance with this study.

Conflict of Interest: None.

4412 words in text

272 words in abstract

1 figure

2 tables 


\begin{abstract}
Introduction. Provoked vestibulodynia (PVD) is a women's sexual health concern which affects $12 \%$ of the general population. Characterized by a provoked pain during vaginal penetration, controlled studies have shown that PVD has a negative impact on the psychological well-being, sexual function, sexual satisfaction, and quality of life of afflicted women. Many cognitive and affective variables may influence the experience of pain and associated psychosexual problems. However, the role of the partner's cognitive responses has been studied very little.
\end{abstract}

Aim. The aim of the present study was to examine the associations between partners' catastrophizing and their perceptions of women's self-efficacy at managing pain, and women's pain intensity, sexual function and sexual satisfaction.

Methods. One hundred and seventy-nine couples ( $M$ age for women $=31, S D=10.0, M$ age for men $=33, S D=10.6$ ) in which the woman suffered from PVD participated in the study. Partners completed the Significant other versions of the Pain Catastrophizing Scale as well as the Painful Intercourse Self-Efficacy Scale.

Main Outcome Measures. Dependent measures were women's responses to (1) the Pain Numeric Visual Analogue Scale, (2) the Female Sexual Function Index, and (3) the Global Measure of Sexual Satisfaction Scale.

Results. Results indicate that higher levels of partner-perceived self-efficacy and lower levels of partner catastrophizing are associated with higher levels of sexual satisfaction and decreased pain intensity in women with PVD, and higher levels of partner-perceived self-efficacy are associated with better sexual function in women. 
Conclusions. Findings suggest that partners' cognitive responses may influence the experience of PVD for women, pointing toward the importance of considering the partner when treating this sexual health problem.

Keywords: catastrophizing, pain, partner, self-efficacy, sexual function, sexual satisfaction, provoked vestibulodynia (PVD), vulvodynia, dyspareunia, couple therapy, vestibulitis. 


\section{Introduction}

Painful sexual intercourse, also known as dyspareunia, is a common and distressing female sexual health condition. According to epidemiological data, approximately $21 \%$ of women between the ages of 18 and 29 suffer from coital pain, as defined by the DSM-IV: a recurrent or persistent genital pain associated with sexual intercourse that is not better accounted for by another diagnosis and is not the direct effect of substance use $(1,2)$. The most common diagnosis causing dyspareunia is provoked vestibulodynia (PVD), a condition which affects $12 \%$ of women in the general population at one point in their life (3). PVD, previously known as vulvar vestibulitis, is described by the International Society for the Study of Vulvovaginal Disease (ISSVD) as a localized provoked vulvodynia, which can be defined as a "burning pain, occurring in the absence of relevant visible findings or a specific, clinically identifiable, neurologic disorder" (4). It is present during vestibular touch or attempted vaginal entry and characterized by tenderness when pressure is exerted to the vestibule (5). Women with PVD report significant impairments in sexual functioning, namely lower levels of sexual desire, arousal and frequency of intercourse (6). Furthermore, they have higher levels of depressive symptoms and psychological distress, as well as lower levels of sexual satisfaction and sexual self-esteem (7, 8). Many women also report feelings of guilt, shame, and inadequacy vis-à-vis their partner (9). The etiology of PVD is thought to be multifactorial, with psychosocial variables such as higher patient levels of anxiety, fear of pain, hypervigilance, and catastrophizing as well as lower levels of patient self-efficacy having been shown to modulate pain intensity and associated sexual difficulties $(10,11,12)$. 
Specifically, catastrophizing, which is defined as an exaggerated and negative set of cognitions during real or anticipated painful experiences, is thought to be the most robust psychological predictor of persistent pain, accounting for 7 to $31 \%$ of pain variation (13). The relationship between catastrophizing and pain has been demonstrated in samples of chronic pain patients, post-surgical pain patients, athletes, as well as asymptomatic individuals (13). In the context of PVD, cross-sectional data show that higher levels of patient catastrophizing are linked to heightened pain (10). Catastrophizing and pain behavior are defined as help seeking and exaggerated displays of illness in the social context (13). Interestingly, catastrophizing, as viewed by the communal coping model, is not necessarily aimed at pain reduction, but more toward maximizing proximity, assistance or empathy from the environment. In this sense, the more an individual catastrophizes, the more his environment perceives him as unable to manage his or her pain (13). Catastrophizing, in the context of the couple relationship, has mostly been studied as a variable pertaining to the patient and how it relates to partner responses (14). For example, higher catastrophizing in patients is associated with greater support from the partner (15), more solicitous behavior (16), or, in contrast, to negative and critical responses from the partner (17). However, the role of partner catastrophizing has received very little empirical attention, in particular in women with PVD.

Self-efficacy, defined as the confidence an individual has in his or her ability to perform a specific task (18), is also an important variable influencing the experience of pain. Higher levels of patient self-efficacy are related to lower degrees of pain and associated symptoms such as disability (19). In addition, it has been found that higher levels of self-efficacy are associated 
with less intense pain in osteoarthritis patients (20) and to lower disability scores in patients with musculoskeletal pain (21). In women with PVD, higher levels of self-efficacy are associated with better sexual functioning and less pain (21). Furthermore, the confidence that patients and family members have in their capacity to manage pain and associated impairments in functioning may be an important factor with regards to both parties' well-being (19).

In PVD, where the partner is not only a close social figure but is often directly involved in the onset and maintenance of the pain, very few studies have explored the role of partner and relationship factors in the experience of pain and other associated symptoms. In a cross-sectional study involving 43 PVD couples, it was found that increased partner solicitude and hostility were correlated with higher pain intensity during vaginal penetration (22). A larger cross-sectional study yielded similar results, showing that higher partner solicitous responses were associated with higher levels of pain intensity and greater sexual satisfaction in women (23). Furthermore, partner responses were not associated with women's sexual function (23). It was also shown that the relationship between partner and woman-perceived partner solicitous responses and pain was mediated by catastrophizing and self-efficacy, and that dyadic adjustment mediated the relationship between women's sexual satisfaction and woman-perceived partner solicitous responses (24). Solicitousness and hostility refer to behavioral responses that directly influence a situation in which pain appears, and are easily observed by both parties. However, few studies have investigated the possible influence of the partner's cognitions, including catastrophizing and self-efficacy, on the experience of PVD. 
Pain catastrophizing may heighten pain and emotional distress in addition to potentially increasing proximity and support from others, notably the spouse (25). Partner catastrophizing has been linked to higher levels of pain, disability and depressive symptoms in individuals with chronic pain, such as osteoarthritis, scoliosis, post-surgical pain, and pain stemming from fractures and bone spurs $(26,27)$. In light of this, and because PVD patients' catastrophizing has been shown to correlate significantly with their pain experience, partner catastrophizing may also be associated with vulvo-vaginal pain, especially given the interpersonal context in which PVD occurs.

Additionally, self-efficacy is another cognitive factor which has an important influence on pain intensity as well as disability. The spouse's perception of his/her partner's self-efficacy with regards to pain management may impact the well-being of both individuals $(19,20)$. Higher caregiver-perceived self-efficacy has been shown to correlate negatively with disability and negative mood in patients experiencing pain from cancer (28). In the case of PVD, where the caregiver (partner) is also in a sense 'causing' the pain, his perception of the woman's selfefficacy may be all the more significant in her experience of pain and associated sexual impairment.

The importance of studying cognitive variables, as opposed to behavioural ones, has been demonstrated in both the fields of pain and sexual dysfunction. In the context of pain, it has been found that cognitive variables are an important factor in the transition from a short-term pain to a long term disabling condition (29). Furthermore, cognitive variables such as catastrophization and self-efficacy are malleable targets of intervention and have a strong prognostic value with 
regards to disability $(21,30)$. When it comes to sexuality, certain cognitions, for example high performance beliefs, are correlated with sexual dysfunction in both men and women (31). Focusing on the patient's and the partner's negative cognitions in the case of PVD could help both individuals manage the pain as well as ameliorate their sexual experience together.

Aim

The goal of the present study was to examine the role of partner-perceived self-efficacy and partner catastrophizing in the experience of pain, sexual functioning and sexual satisfaction of women with PVD.

The main hypotheses were that higher levels of partner-perceived self-efficacy and lower levels of partner catastrophizing would be associated with decreased pain intensity, greater sexual satisfaction, and better sexual function in women with PVD.

\section{Methods}

Participants

Participating couples were recruited through health professional referrals and advertisements in local newspapers, women's magazines as well as via our laboratory's website and flyers on university billboards. Participants were initially screened by telephone in order to determine their eligibility based on selection criteria for the study. Inclusion criteria consisted of the following: 1) pain during intercourse causing subjective distress, present during most penetration attempts ( $75 \%$ of the time), for at least 6 months; 2$)$ pain limited to activities where there is penetration or pressure applied to the vestibule (e.g., cycling); 3) women aged between 18 and 45 ; 4) couples in current relationship for at least 6 months. Exclusion criteria were: 1) 
pain not clearly linked to pressure to the vestibule; 2) major medical or psychiatric illness; 3) presence of an active yeast infection, vaginismus, deep dyspareunia, or dermatological lesions; 4) pregnancy. Partners had no additional inclusion criteria, and were asked to participate via their eligible spouses.

Following a detailed telephone screening procedure, eligible couples were sent selfreport questionnaires and consent forms via regular mail (anonymously), along with preaddressed and pre-stamped envelopes. Women recruited through health professionals were screened and given envelopes in person, for themselves and their partners. In order to compensate couples for their participation, a thirty minute telephone consultation with a sexologist member of the research team was offered. The entire protocol was approved by our institution's ethical review board.

\section{Measures}

Main Outcome Measures: Women's Questionnaires

\section{Pain Intensity}

Pain intensity was measured using the Pain Numeric Visual Analogue Scale (PNVAS), a horizontal $10 \mathrm{~cm}$ line, with indications at both extremities: at the left " 0 - no pain", and at the right "10 - worst pain ever", with all 9 digits in between (see figure 1). Participants were invited to circle the answer best describing their pain during the last 6 months. Validity of this measure has been well demonstrated in past research as the PNVAS has been found to correlate significantly with other pain measures (32). 
Sexual Functioning

The Female Sexual Function Index (FSFI; 33) was also completed by women in the sample. The FSFI is comprised of 19 items measuring 5 dimensions: 1) desire, 2) lubrication, 3) orgasm, 4) satisfaction, and 5) pain. This questionnaire has demonstrated very good psychometric properties (34).

\section{$\underline{\text { Sexual Satisfaction }}$}

Sexual satisfaction was measured using the Global Measure of Sexual Satisfaction scale (GMSEX; 35), which is comprised of 5 items. Participants must rate their relationship with their partner on five 7-point bipolar scales: good-bad, pleasant-unpleasant, positive-negative, satisfying-unsatisfying, valuable-worthless. Reliability and validity for this scale has been well demonstrated (35).

Independent Variables: Partners' Questionnaires

\section{Catastrophizing}

Catastrophizing was assessed using the Significant Other Version of the Pain Catastrophizing Scale (S-PCS; 26, 36). This questionnaire includes 13 items measuring 3 dimensions: 1) rumination, 2) magnification, and 3) helplessness. The S-PCS has been shown to be a reliable and valid measure, with a stable factor structure across gender and racial groups (24) and has been used in a variety of chronic pain populations $(24,37)$.

\section{$\underline{\text { Self-Efficacy }}$}

Romantic partners' perception of women's pain self-efficacy was measured using the partner version of the Painful Intercourse Self-Efficacy Scale (PISES; 10), an adapted version of 
the Arthritis Self-Efficacy Scale (ASES; 38). This questionnaire is comprised of 20 items assessing 3 dimensions: 1) pain, 2) functioning, and 3) other symptoms. This adaptation has been used in other studies carried out by our research group and has demonstrated good internal consistency as well as a factor structure identical to the original version (10).

\section{Data analysis}

Prior to the analysis, the data were examined for outliers, missing data, and assumption violations, as well as to target potential covariates. Pearson correlations (for continuous variables), Spearman correlations (for non-continuous variables) and descriptive statistics were computed. Multiple regressions were conducted in order to evaluate the relative contribution of partner catastrophizing and partner-perceived self-efficacy to women's pain intensity, sexual satisfaction and sexual functioning, using a $\rho<.05$ level of significance.

\section{Results}

Sample characteristics

The final sample size was comprised of 179 couples, selected from a pool of 233 couples. Of the initial pool, 17 couples were excluded because one of the partners did not return their questionnaires. Six couples were removed from the database on the basis of low scores on the Pain Intensity Visual Analogue Scale (0 or 1), which made them outliers. The remaining 31 couples were excluded because of missing data. Of the 179 couples, 78 were recruited following a visit with a gynecologist (and received a PVD diagnosis), 87 were recruited through advertisements in magazines, newspapers, websites, and on billboards, and the remaining 14 
couples were recruited through other sources, such as referrals from other medical and nonmedical health professionals, word of mouth, previous studies, etc.

Sociodemographic characteristics of study participants are presented in Table 1. Mean age for women was 31 years $(\mathrm{SD}=10.0)$ and that of partners was 33 years $(\mathrm{SD}=10.6)$. Participants were found to be fairly well educated, with a mean of 16 years of education for women and partners ( $\mathrm{SD}=2.9$ and 3.2, respectively). Mean relationship duration was of 6 years $(\mathrm{SD}=6.6)$, but with much variation between couples. Women reported a mean pain duration of 6 years $(\mathrm{SD}=6.0)$. These results mirror those obtained in previous studies pertaining to PVD (39, $40)$.

Mean scores and SD for sexual functioning (FSFI-W), sexual satisfaction (GMSEX-W), and pain intensity (PNVAS-W), for women, as well as catastrophizing (PCS-P) and self-efficacy (PISES-P), for partners, can also be found in Table 1. The mean level of catastrophizing in partners $($ mean $=28.6 ; \mathrm{SD}=9.7)$ suggests a high degree of catastrophizing, with scores above 24 or below 15 targeting high and low catastrophizers, respectively (36). However, no cutoffs have been reported in peer reviewed literature concerning clinical outcomes. The mean level of perceived self-efficacy by partners (mean $=58.9 ; \mathrm{SD}=15.7$ ) is similar to that of comparable studies using the PISES (10). For dependent variables, the mean sexual functioning score for women $($ mean $=17.7 ; \mathrm{SD}=4.1)$ indicates sexual dysfunction in the clinical range, the cutoff point being below 26 (41). The mean level of sexual satisfaction of women $($ mean $=22.9 ; \mathrm{SD}=$ 6.2) resembled that reported in other studies conducted with samples of women with PVD (42). The mean score of pain intensity in women (mean $=7.2 ; \mathrm{SD}=1.7$ ) indicates that the experience 
of pain from dyspareunia resembles that of other chronic pain populations (43), as well as that of similar studies pertaining to PVD $(39,44)$.

Zero-Order Correlations among Variables

Simple correlations between measures of pain intensity (PNVAS-W), sexual satisfaction (GMSEX-W) and sexual functioning (FSFI-W) of women (dependent variables), as well as measures of catastrophizing (PCS-P) and perceived self-efficacy (PISES-P) of partners (independent variables) are show in Table 2. First, none of the sociodemographic variables correlated significantly with the dependent measures. Partner catastrophizing (PCS-P) was significantly correlated with women's pain intensity (PNVAS-W; $r=0.35, \rho<0.01$ ) and sexual satisfaction (GMSEX-W; $r=-0.19, \rho<0.05)$, but not sexual functioning (FSFI-W; $r=-0.053)$. Partner's perception of women's self-efficacy (PISES-P) was found to correlate significantly with women's pain intensity (PNVAS-W; $r=-0.31, \rho<0.01$ ), sexual satisfaction (GMSEX-W; $r$ $=0.21, \rho<0.01)$, and sexual functioning $($ FSFI-W; $r=0.21, \rho<0.01)$.

\section{Correlates of Pain Intensity}

A multiple linear regression analysis was conducted in order to determine the relative contribution of each partner variable to pain intensity (PNVAS-W). The independent variables, i.e. partner catastrophizing (PCS-P) and perceived self-efficacy (PISES-P), were added together to the regression model to evaluate their relative contribution to vulvo-vaginal pain intensity. The model significantly explained $15.8 \%$ of the variance in the pain intensity of women with PVD $[F(2,176)=17.734, P<0.001]$. Examination of the $\beta$ weights for this model indicated that both 
catastrophizing (PCS-P) and self-efficacy (PISES-P) contributed unique variance (respectively $\beta$ $=0.28, P<0.001$, and $\beta=-0.22, P=0.003$ ) to the prediction of intercourse pain intensity.

\section{Correlates of Sexual Satisfaction}

A second linear regression analysis was carried out examining the contribution of partner pain catastrophizing (PCS-P) and perceived self-efficacy (PISES-P) to women's level of sexual satisfaction (GMSEX-W). This model accounted significantly for $5.2 \%$ of the variance in sexual satisfaction of the women in our sample $[\mathrm{F}(2,176)=5.896, \mathrm{P}=0.003]$. An exploration of $\beta$ weights showed that only self-efficacy (PISES-P) contributed unique variance $(\beta=0.171, P=$ 0.028) to sexual satisfaction. However, a trend was also found for the pain catastrophizing scale $(\beta=-0.138, P=0.075)$.

\section{Correlates of Sexual Functioning}

Finally, a linear regression analysis was performed in order to evaluate the relative contribution of partner variables (PCS-P and PISES-P) to global sexual functioning (FSFI-W) of women with PVD. The resulting model significantly explained 3.1\% of the variance in sexual functioning $[F(2,176)=3.86, P=0.023]$. A further examination of $\beta$ weights showed that only self-efficacy (PISES-P) offered unique variance $(\beta=0.208, P=0.008)$ to the prediction of sexual functioning.

\section{Discussion}

The aim of the present paper is to report on the role of partners' catastrophizing and 
perceived self-efficacy in the experience of pain, sexual functioning and sexual satisfaction of women with PVD. As hypothesized, higher levels of partner-perceived self-efficacy and lower levels of partner catastrophizing were associated with less pain intensity and greater sexual satisfaction in women with PVD. These results concur with those of past studies pertaining to chronic pain, in that relationship components play a significant role in the experience of pain and subsequent disability (45). The hypothesis concerning sexual function was partly confirmed, in that only higher levels of partner-perceived self-efficacy contributed to overall better sexual function.

First, the finding that higher levels of partner-perceived self-efficacy and lower levels of partner catastrophizing were associated with decreased pain intensity and that each contributed unique variance to the outcome, is in line with a previous study showing that partner catastrophizing and self-efficacy partially mediated the association between higher partnerperceived solicitous responses and higher women's pain intensity (24). Furthermore, catastrophizers not only experience greater pain, they also perceive more intense pain in others as well (46), which may in turn influence their behavior towards a sick spouse, making them more solicitous or hostile. It is known that partner solicitousness and hostility are associated with pain intensity in women with $\operatorname{PVD}(8,23)$. Further, partners' catastrophizing about their spouses' pain has been linked to higher depressive symptoms for themselves, and has been shown to strengthen the association between patients' pain catastrophizing and depressive symptoms (26). It could be hypothesized that partners who catastrophize verbalize their thoughts about pain, 
creating a negative and exaggerated dialogue, which in turn heightens pain awareness and catastrophizing in the patient, who then experiences more pain.

Self-efficacy is also an important cognitive variable when studying pain and may have interpersonal repercussions. In the present study, higher partner-perceived self-efficacy was associated with decreased pain intensity. This result corroborates findings from the chronic pain literature indicating that instances in which self-efficacy is low are likely to lead to greater pain and disability (47). Moreover, the fact that both partner self-efficacy and catastrophizing together significantly contributed to pain is supported by another study which demonstrated that higher pain catastrophizing is associated with lower self-efficacy, in that self-efficacy for pain control mediates the relationship between catastrophizing and pain (48). Also, partners who believed that the spouse's pain is controllable were more likely to give lower pain and disability ratings, as were their spouses, who also showed less pain behavior (49). Furthermore, in lung cancer patients, it was found that caregivers' ratings of their own self-efficacy for helping the patient manage symptoms were significantly related to the patient's functional well being, physical well being, and depressive symptoms (19). The mechanism underlying the link between self-efficacy and pain may have to do with personal expectations regarding one's ability to perform a task, e.g., manage pain, and with determining whether coping behaviors will be initiated in the face of obstacles and aversive experiences, or if avoidance behaviors will be chosen. Once an individual persists in activities that are at first perceived as threatening but eventually reveal themselves to be relatively safe, self-efficacy is enhanced and avoidance behavior is reduced (18). Therefore, if a patient feels unable to manage pain, it is likely that he or she will avoid using pain management 
strategies, therefore likely heightening the experience of pain (19). If partners sense that their spouse with PVD is unable to manage her pain, they may inadvertently encourage avoidance behaviors in the patient (23). More specifically, a man who does not believe his partner can manage her PVD pain may avoid initiating sexual activity and even engaging in other forms of physical intimacy, which will in turn encourage the woman to avoid facing her fear of pain, therefore not practicing strategies for reducing pain-related anxiety and thus potentially heightening the pain experience.

Second, the finding that partners' higher levels of perceived self-efficacy and lower levels of catastrophizing lead to higher levels of sexual satisfaction, with only self-efficacy contributing unique variance, is interesting in so far as very few studies to date have investigated the link between these variables, especially with regards to self-efficacy and sexual satisfaction. However, one can assume that feeling that your partner does not believe in your ability to manage your pain may generate a context of mistrust, which may lead to less enjoyment in a sexual interaction. In the same way, partners of women with PVD who approach a sexual interaction with more equanimity may be viewed as being focused on the women's pleasure and sensitive to their needs, leading to higher sexual satisfaction, while higher negative partner responses may be interpreted as an absence of sensitivity and therefore generate a context which hinders intimacy and sexual satisfaction (23).

Finally, the finding that partners' higher perceived self-efficacy and higher catastrophizing lead to better sexual functioning, with only self-efficacy contributing unique variance, only partially confirms our initial hypothesis. On the one hand, higher partner- 
perceived self-efficacy is expected to lead to better sexual function. For example, it was found that, in osteoarthritis patients, higher levels of caregiver-perceived self-efficacy were significantly associated with lower levels of patient physical and psychological disability, as well as with lower levels of partner negative affect (20).On the other hand, catastrophizing has generally been associated with heightened disability (13). It is possible that the reason why these results differ for PVD couples is that many women continue to have sex out of guilt towards their partner, and frequency of intercourse is one of the dimensions of sexual function (50). In this sense, maybe sexual frequency is less of a true indication of sexual function than, for example, satisfaction or desire. Furthermore, it has been found that sexual functioning and pain may be somewhat independent and distinct phenomena, as these two variables are not significantly correlated (51). The fact that catastrophizing leads to greater pain but is not significantly associated with better sexual function further supports this distinction. As for higher partner-perceived self-efficacy being linked to better sexual function, a cognitive-behavioral framework would predict that if a partner believes in his spouse's ability to manage her pain, he will encourage her in activities that may elicit fear of pain (e.g., activities related to sex, including but not limited to intercourse), therefore her own self-efficacy will be enhanced by progressively learning how to manage her fear, and avoidance behaviors will progressively be reduced. A partner with higher perceived self-efficacy may also be more relaxed during the sexual interaction and more focused on pleasuring the woman rather than being concerned about her pain, which may be associated with better sexual function in both partners. 
In short, results suggest that partners' cognitions are associated with the experience of PVD in women. This corroborates results from chronic pain studies, in which it has been demonstrated that partners play an important role in the patients' pain intensity and disability. Consequently, the social context must be taken into account in a multidimensional conceptualization of PVD and more research is needed to better understand the complex interactions between partner cognitions, emotions and behaviors and women with PVD's pain and sexual outcomes.

It is important to note certain limitations of this study. First, because of the crosssectional nature of the design, a causal association between the independent and dependent variables cannot be established. It could be that partners of women who report higher levels of pain will catastrophize more simply because her pain behaviors signal intense pain. Further studies should be conducted using a longitudinal methodology in order to establish temporal relations between variables. Second, although the study criterion corresponded to a PVD diagnosis, participants were recruited from various sources (ads in newspapers and magazines, flyers on billboards, etc.) and only a portion were referred by a health professional with an official diagnosis. That said, all participants were screened using the PVD diagnostic criteria and sample characteristics do not significantly differ from those in studies in which a gynecological examination was performed (10). Finally, all measures were self-report. Nonetheless, all questionnaires had strong psychometric properties.

Despite these limitations, this study has a number of strengths. It shows that partner cognitive responses to pain may contribute to increased pain intensity and diminished sexual 
satisfaction and function in women with PVD. This provides additional support for the role of dyadic variables in the experience of painful sexual intercourse.

Theoretically, this implies that the cognitive-behavioral model can serve to partially explain the role the partners may take on as a reinforcing agent. Furthermore, this adds additional evidence to Sullivan's Communal Coping Model (CCM), which states that catastrophizing may serve to evoke empathy, maximize proximity or to solicit assistance from others in the social environment in order to increase the chances that distress will be managed within an interpersonal context (13). One could even hypothesize that the CCM may not only involve catastrophizing, but other cognitive or affective variables, such as self-efficacy. Indeed, poor self-efficacy may also elicit behavior from others in the social environment, which may in turn affect pain and associated symptoms. Finally, these results may be of use in developing clinical interventions focused on the relationship aspects of PVD by evaluating and working on both partners' cognitive reactions to the pain. Explaining to the couple how they both have a role to play in the experience of PVD may serve to increase partner implication in treatment, diminish the identified patient's feelings of guilt and help in motivation towards change.

\section{Conclusion}

In conclusion, our findings suggest that partners' cognitive variables may influence the experience of PVD for women. Specifically, higher levels of partner-perceived self-efficacy and lower levels of partner catastrophizing are associated with decreased pain intensity and greater sexual satisfaction in women with PVD, whereas only higher levels of perceived self-efficacy were related to overall better sexual function in women. These results demonstrate the 
importance of evaluating dyadic factors at the onset of a care episode as an integral part of a comprehensive evaluation when treating this women's sexual health problem. Addressing dyadic factors early in the management course of PVD may heighten the success of the therapeutic interventions. 
Figure 1. Pain Numeric Visual Analogue Scale (PNVAS)

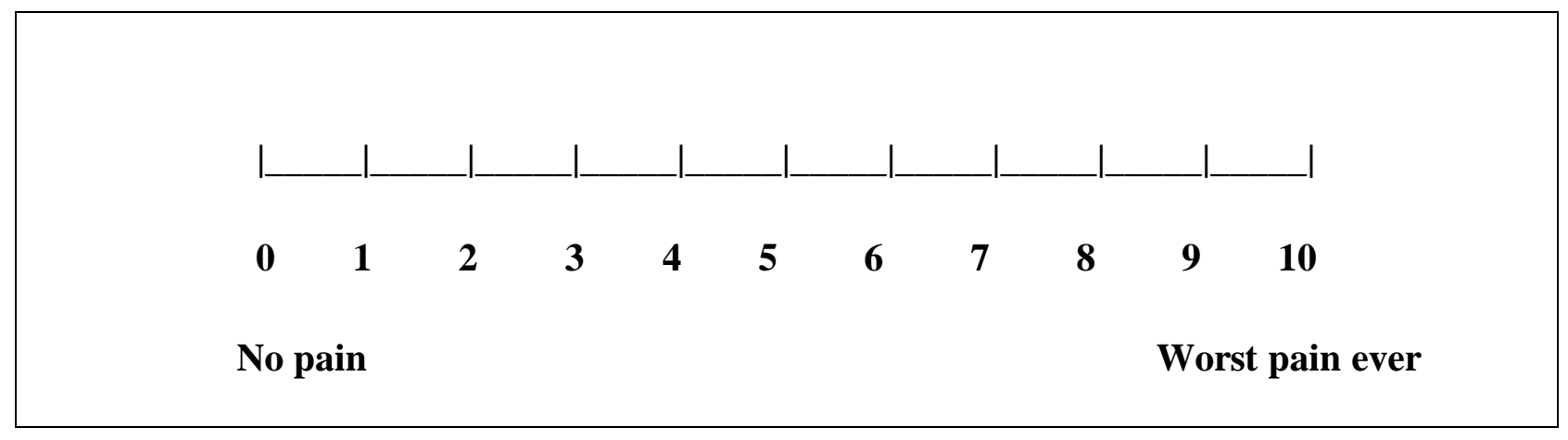


Table 1. Descriptive statistics of the sample.

\begin{tabular}{|c|c|c|}
\hline & $\mathrm{N}$ or $\mathrm{X}$ & $\mathrm{SD}$ or $\%$ \\
\hline \multicolumn{3}{|l|}{ Characteristics } \\
\hline Age of woman & 30,50 & 10,02 \\
\hline Age of partner & 33,30 & 10,57 \\
\hline Education of woman & 16,20 & 2,85 \\
\hline Education of partner & 15,66 & 3,21 \\
\hline \multicolumn{3}{|l|}{ Marital status } \\
\hline Dating & 25 & 14,0 \\
\hline Cohabitating & 112 & 62,6 \\
\hline Married & 41 & 22,9 \\
\hline Relationship duration & 6,36 & 6,58 \\
\hline Pain duration & 5,57 & 5,95 \\
\hline \multicolumn{3}{|c|}{ Cultural affiliation of woman } \\
\hline French Canadian & 163 & 91,1 \\
\hline English Canadian & 2 & 1,1 \\
\hline European & 6 & 3,4 \\
\hline Other & 8 & 4,5 \\
\hline Cultural affiliation of & & \\
\hline
\end{tabular}




\begin{tabular}{lcr}
\hline French Canadian & 134 & 74,9 \\
English Canadian & 11 & 6,1 \\
European & 6 & 3,4 \\
Other & 8 & 19,9 \\
PNVAS-W & 7,21 & 1,65 \\
GMSEX-W & 22,93 & 6,24 \\
FSFI-W & 17,71 & 4,05 \\
PCS-P & 28,61 & 9,65 \\
PISES-P & 58,88 & 15,69 \\
\hline N = 179 & & \\
\hline PNVAS-W = Pain Numeric Visual Analogue Scale - Women's Version; & \\
PMSE-W & \\
\end{tabular}


Table 2. Zero-order correlations between pain intensity, sexual satisfaction, sexual functioning, and partner variables (pain catastrophizing and self-efficacy)

\begin{tabular}{|c|c|c|c|c|}
\hline & PNVAS - W & GMSEX-W & FSFI-W & PCS-P \\
\hline GMSEX-W & -.086 & & & \\
\hline FSFI-W & $-.258^{* *}$ & -.008 & & \\
\hline PCS-P & $.352 * *$ & $-.191 *$ & -.053 & \\
\hline PISES-P & $-.308 * *$ & $.214 * *$ & $.205^{* *}$ & $-.313 * *$ \\
\hline \multicolumn{5}{|c|}{$* \rho<0.05, * * \rho<0.01, * * * \rho<0.001$. } \\
\hline \multicolumn{5}{|c|}{ PNVAS-W = Pain Numeric Visual Analogue Scale - Women's Version; } \\
\hline \multicolumn{5}{|c|}{ GMSEX-W = Global Measure of Sexual Satisfaction - Women's Version; } \\
\hline \multicolumn{5}{|c|}{ FSFI-W = Female Sexual Function Index - Women's Version; } \\
\hline \multicolumn{5}{|c|}{ PCS-P = Pain Catastrophizing Scale - Partner Version; } \\
\hline \multicolumn{5}{|c|}{ PISES-P = Painful Intercourse Self-Efficacy Scale - Partner Version } \\
\hline
\end{tabular}




\section{References}

1. Laumann EO, Paik A, Rosen RC. Sexual dysfunction in the United Sates. Journal of the American Medical Association. 1999; 281: 537-44.

2. American Psychiatric Association. Diagnostic and statistical manual of mental disorders: DSMIV. 4th ed. Washington, DC: American Psychiatric Association; 1994. 866 p.

3. Harlow BL, Wise LA, Stewart EG. Prevalence and predictors of chronic lower genital tract discomfort. Am J Obstet Gynecol. 2001; 185: 545-50.

4. Haefner HK., Collins ME, Davis GD, Edwards L, Foster DC, Hartmann ED, et al. The vulvodynia guideline. J Low Genit Tract Dis. 2005; 9: 40-51.

5. Friedrich EG. Vulvar vestibulitis syndrome. Journal of Reproductive Medicine. 1987; 32: 110-4.

6. Arnold LD, Bachmann GA, Rosen R, et al. Vulvodynia: characteristics and associations with comorbidities and quality of life. Obstet Gynecol. 2006; 107: 617-24.

7. Gates E A, Galask RP. Psychological and sexual functioning in women with vulvar vestibulitis. Journal of Psychosomatic Obstetric Gynaecology. 2001; 22(4): 221-8.

8. Desrochers G, Bergeron S, Landry T, Jodoin M. Do psychosexual factors play a role in the etiology of provoked vestibulodynia? A critical review. Journal of Sex \& Marital Therapy. 2008; 34: 198-226.

9. Ayling K, Ussher JM. "If Sex Hurts, Am I Still a Woman?" The Subjective Experience of Vulvodynia in Hetero-Sexual Women. Arch Sex Behav. 2008; 37: 294-304. 
10. Desrochers G, Bergeron S, Khalifeé S, Dupuis MJ, Jodoin M. Fear avoidance and pain selfefficacy in relation to pain and sexual impairment in women with provoked vestibulodynia. Clinical Journal of Pain. 2009; 25(6): 520-7.

11. Desrochers G, Bergeron S, Khalifé S, Dupuis MJ, Jodoin M. Provoked vestibulodynia:

Psychological predictors of topical and cognitive-behavioral treatment outcome. Behaviour Research and Therapy. 2010; 48: 106-15.

12. Payne KA, Binik YM, Amsel R, Khalife S. When sex hurts, anxiety and fear orient attention towards pain. European Journal of Pain. 2004; 9: 427-36.

13. Sullivan MJL, Thorn B, Haythornthwaite JA, Keefe F, Martin M, Bradley LA, Lefebvre JC. Theoretical Perspectives on the Relation Between Catastrophizing and Pain. The Clinical Journal of Pain. 2001; 17: 52-64.

14. Quartana PJ, Campbell CM, Edwards RR. Pain catastrophizing: a critical review. Expert Rev Neurother. 2009; 9(5): 745-58.

15. Keefe FJ, Lipkus I, Lefebvre JC, Hurwitz H, Clipp E, Smith J, Porter L. The social context of gastrointestinal cancer pain: a preliminary study examining the relation of patient pain catastrophizing to patient perceptions of social support and caregiver stress and negative responses. Pain. 2003; 103(1-2): 151-6.

16. Giardino ND, Jensen MP, Turner JA, Ehde DM, Cardenas DD. Social environment moderates the association between catastrophizing and pain among persons with a spinal cord injury. Pain. 2003; 106(1-2): 19-25. 
17. Boothby JL, Thorn BE, Overduin LY, Ward CL. Catastrophizing and perceived partner responses to pain. Pain. 2004; 109(3): 500-6.

18. Bandura A. Self-efficacy: The exercise of control. New York: W.H. Freeman; 1997.

19. Porter LS, Keefe FJ, Garst J, McBride CM., Baucom D. Self-efficacy for managing pain, symptoms, and function in patients with lung cancer and their informal caregivers: associations with symptoms and distress. Pain. 2008; 137: 306-15.

20. Porter LS, Keefe FJ, Wellington C, de Williams A. Pain Communication in the Context of Osteoarthritis: Patient and Partner Self-efficacy for Pain Communication and Holding Back from Discussion of Pain and Arthritis-related Concerns. The Clinical Journal of Pain. 2008; 24(8): 662-8.

21. Denison E, Asenlöf P, Lindberg P. Self-efficacy, fear avoidance, and pain intensity as predictors of disability in sub-acute and chronic musculoskeletal pain patients in primary health care. Pain. 2004; 111: 245-52.

22. Desrosiers M, Bergeron S, Meana M, Leclerc B, Binik YM, Khalifé S. Psychosexual Characteristics of Vestibulodynia Couples: Partner Solicitousness and Hostility are Associated with Pain. Journal of Sexual Medicine. 2008; 5: 418-27.

23. Rosen NO, Bergeron S, Leclerc B, Lambert B, Steben M. Woman and partner-perceived partner responses predict pain and sexual satisfaction in provoked vestibulodynia (PVD) couples. Journal of Sexual Medicine. 2010; 7: 3715-24. 
24. Rosen NO, Bergeron S, Lambert B, Steben M. Provoked vestibulodynia: Partner and patient catastrophizing and dyadic adjustment as mediators of the associations between partner responses, pain and sexual satisfaction. Archives of Sexual Behavior. 2012; 41(1).

25. Thorn BE, Ward LC, Sullivan MJL, Boothby JL. Communal coping model of catastrophizing: Conceptual model building. Pain. 2003; 106: 1-2.

26. Cano A, Leonard MT, Franz A. The significant other version of the Pain Catastrophizing Scale (PCS-S): Preliminary validation. Pain. 2005; 119: 26-37.

27. Cano A. Pain catastrophizing and social support in married individuals with chronic pain: the moderating role of pain duration. Pain 2004;110: 656-64.

28. Keefe FJ, Ahles T, Porter L, Sutton L, McBride C, Pope MS, McKinstry E, Furstenberg C, Dalton J, Baucom DA. The self-efficacy of family caregivers for helping cancer patients manage pain at end-of-life. Pain. 2003; 103: 157-62.

29. Casey C, Greenberg M, Nicassio P, Harpin R, Hubbard D. Transition from acute to chronic pain and disability: A model including cognitive, affective, and trauma factors. Pain. 2008; 134: 69-79.

30. Pincus T, Burton A, Vogel S, Field A. A systematic review of psychological factors as predictors of chronicity/disability in prospective cohorts of low back pain. Spine. 2002; 27(5): 109-20.

31. Nobre PJ, Pinto-Gouveia J, Gomes FA. Sexual dysfunctional beliefs questionnaire: An instrument to assess sexual dysfunctional beliefs as vulnerability factors to sexual problems. Sexual and Relationship Therapy. 2003; 18: 171-204. 
32. Jensen MP, Karoly P. Self-report scale and procedures for assessing pain in adults. In Turk DC, Melzack R, editors. Handbook of pain assessment . New York : The Guilford Press; 2001. p. $15-34$.

33. Rosen R, Brown C, Heiman J, Leiblum S, Meston C, Shabsigh R, Furguson D, D'Agostino R. The Female Sexual Function Index (FSFI): A multidimensional self-report instrument for the Assessment of Female Sexual Function . Journal of Sex and Marital Therapy. 2000; 26(2): 191-208.

34. Daker-White G. Reliable and valid self-report outcome measures in sexual (Dys)functional systematic review. Archives of Sexual Behavior. 2002; 31(2): 197-209.

35. Lawrance K, Byers ES. Interpersonal Exchange Model of Sexual Satisfaction Questionnaire. In: Davis CM, Yarber WL, Baureman R, Schreer G, Davis SL, editors. Sexuality related measures: A compendium. 2nd ed. Thousand Oaks, CA: Gage; 1998. p. 514-9.

36. Sullivan MJL, Bishop S, Pivik J. The Pain Catastrophizing Scale: development and validation. Psycholological Assessment. 1995; 7: 524-32.

37. Leonard M, Cano A. Pain Affects Spouses too: Personal Experience with Pain and Catastrophizing as Correlates of Spouse Distress. Pain. 2006; 126: 139-46.

38. Lorig K, Chastain R, Ung E, Shoor S, Holman H. Development and evaluation of a scale to measure perceived self-efficacy in people with arthritis. Arthritis Rheum. 1989; 32: 37-44.

39. Bergeron S, Binik YM, Khalifé S, Pagidasc K, Glazerd HI, Meana M, Amsela R. A randomized comparison of group cognitive-behavioral therapy, surface electromyographic biofeedback, 
and vestibulectomy in the treatment of dyspareunia resulting from vulvar vestibulitis. Pain. 2001; 91: 297-306.

40. Brotto LA, Basson R, Gehring D. Psychological profiles among women with vulvar vestibulitis syndrome: A chart review. Journal of Psychosomatic Obstetrics \& Gynecology. 2003; 24: 195-203.

41. Wiegel M, Meston C, Rosen R. The female sexual function index (FSFI): cross-validation and development of clinical Cutoff scores. Journal of Sex and Marital Therapy. 2005; 31: 1-20.

42. Jodoin M, Bergeron S, Khalifé S, Dupuis MJ, Desrochers G, Leclerc B. Attributions about pain as predictors of psychological symptomatology, sexual function, and dyadic adjustment in women with vestibulodynia. Archives of Sexual Behavior. 2011; 40(1): 87-97.

43. Grilo RM, Treves R, Preux PM, Vergne-Salle P, Bertin P. Clinically relevant VAS pain score change in patients with acute rheumatic conditions. Joint Bone Spine. 2007; 74: 358-61.

44. Meana M, Binik YM, Khalifé S, Cohen D. Dyspareunia: Sexual dysfunction or pain syndrome? Journal of Nervous and Mental Disease. 1997; 185: 561-9.

45. Leonard MT, Cano A, Johansen AB. Chronic Pain in a Couples Context: A Review and Integration of Theoretical Models and Empirical Evidence. The Journal of Pain. 2006; 7(6): $377-90$.

46. Sullivan MJL, Martel MO, Tripp DA, Savard A, Crombez G. Catastrophic thinking and heightened perception of pain in others. Pain. 2006; 123: 37-44.

47. Woby SR, Urmston M, Watson PJ. Self-efficacy mediates the relation between pain-related fear and outcome in chronic low back pain patients. European Journal of Pain. 2007; 11: 711-8. 
48. Shelby RA, Somers TJ, Keefe FJ, Pells JJ, Dixon KE, Blumenthal JA. Domain Specific SelfEfficacy Mediates the Impact of Pain Catastrophizing on Pain and Disability in Overweight and Obese Osteoarthritis Patients. Journal of Pain. 2008; 9(10): 912-9.

49. Cano A, Miller LR, Loree A. Spouse beliefs about partner chronic pain. Journal of Pain. 2009; 10: 486-92.

50. Gordon AS, Panahian-Jand M, McComb F, Melegari C, Sharp S. Characteristics of women with vulvar pain disorders: responses to a Web-based survey. Journal of Sex and Marital Therapy. $2003 ; 29(1): 45-58$.

51. Bergeron S, Rosen NO, Morin M. Genital pain in women: Beyond interference with intercourse. Pain. 2011; 152: 1223-5. 